\title{
LIVER
}

\section{Evidence for altered vascular responses to exogenous endothelin- 1 in patients with advanced cirrhosis with restoration of the normal vasoconstrictor response following successful liver transplantation}

\author{
R B Vaughan, P W Angus, J P F Chin-Dusting
}

See end of article for authors' affiliations

\section{Correspondence to:} Professor P W Angus, Victorian Liver Transplant Unit, Austin and Repatriation Medical Centre, Studley Rd, Heidelberg, Melbourne, VIC 3084, Australia: Peter.Angus@armc.org.au

Accepted for publication 9 June 2003

\begin{abstract}
Background and aims: There is evidence that dampened responses to endogenous vasoconstrictors contribute to the hyperdynamic circulation that is characteristic of advanced cirrhosis. The aim of this study was to determine whether there is an altered vascular responsiveness to the endothelium derived constricting factor endothelin-1 (ET-1) in patients with decompensated chronic liver disease which might contribute to this abnormal circulatory state, and whether normal endothelin responses are restored following liver transplantation.

Methods: Using forearm plethysmography, we studied the vascular response to an intra-arterial ET-1 infusion in six patients with end stage cirrhosis, before and after liver transplantation, compared with six normal control subjects. Responses to the selective endothelin $A\left(E T_{A}\right)$ receptor subtype antagonist, $B Q 123$, were also examined.

Results: The forearm vessels of patients with cirrhosis vasodilated in response to ET-1 infusion while in healthy controls a marked vasoconstriction response was observed $(p<0.0001$, area under the curve timeblood flow was normal compared with the cirrhosis groups, ANOVA). Prior to commencement of liver transplant surgery, cirrhotic patients were confirmed to have a hyperdynamic circulation with a high cardiac index $\left(4.07(0.23) \mathrm{l} / \mathrm{min} / \mathrm{m}^{2}\right.$ (normal range $\left.2.8-3.6 \mathrm{l} / \mathrm{min} / \mathrm{m}^{2}\right)$ ) and low systemic vascular resistance index (1284 (115) dyn $\times \mathrm{s} / \mathrm{cm}^{5} / \mathrm{m}^{2}$ (normal range $\left.1760-2600 \mathrm{dyn} \times \mathrm{s} / \mathrm{cm}^{5} / \mathrm{m}^{2}\right)$ ). Following transplantation, normal vasoconstrictor responses to ET-1 were restored. Responses to BQ123 were not different in patients with advanced cirrhosis compared with controls.

Conclusion: In patients with end stage cirrhosis, ET-1 produces vasodilatation at a dose that causes marked vasoconstriction in normal control subjects. This effect is not attributable to impairment of $\mathrm{ET}_{\mathrm{A}}$ receptor responses. Our findings suggest that altered endothelin responses may contribute to the generalised dilatation of the circulation that occurs in patients with advanced liver disease.
\end{abstract}

$\mathrm{T}$ he generalised vasodilatation that occurs in patients with advanced cirrhosis leads to the development of a hyperdynamic circulatory state, ${ }^{1-3}$ characterised by high cardiac output, low vascular resistance, low systemic blood pressure, and marked sympathetic activation. ${ }^{4}$ These changes contribute to many of the complications of the condition, including fluid retention with ascites formation, hepatopulmonary syndrome, and the hepatorenal syndrome. ${ }^{5}$ However, the mechanisms responsible for this vasodilatation have not been fully defined.

Noradrenaline, angiotensin II, $^{6}$ and arginine vasopressin ${ }^{7}$ levels are elevated in the circulation of patients with cirrhosis, with the degree of elevation being greatest in those with advanced disease in whom vasodilatation is most prominent. ${ }^{8}$ This suggests that vasodilatation is associated with impairment of normal vasoconstriction responses to circulating vasopressors. Endothelin-1 (ET-1) is a 21 amino acid vasoactive peptide that has the capacity to produce both vasoconstrictor ${ }^{9}$ and vasodilatory responses. ${ }^{10}$ Two endothelin receptor subtypes, nominated endothelin- $\mathrm{A}\left(\mathrm{ET}_{\mathrm{A}}\right)$ and endothelin- $\mathrm{B}\left(\mathrm{ET}_{\mathrm{B}}\right)$ receptors, have been cloned and characterised to date. $\mathrm{ET}_{\mathrm{A}}$ and $\mathrm{ET}_{\mathrm{B}}$ receptors are present on vascular smooth muscle and binding of endothelin to these receptors leads to vasoconstriction. $\mathrm{ET}_{\mathrm{B}}$ receptors are also found on vascular endothelial cells and can mediate vasodilatation through release of endothelium derived relaxing factors (EDRFs), such as nitric oxide (NO) and vasodilator prostanoids. In normal physiology, basal ET-1 release contributes to maintenance of vascular tone, predominantly through its vasoconstrictor action on vascular smooth muscle, ${ }^{11}$ but its effect in cirrhotic patients who have a vasodilated circulation is unclear.

Recent work in patients with well compensated cirrhosis and normal vascular tone has demonstrated reduced vasoconstriction responses to this peptide. ${ }^{12}$ However, its effects in patients with advanced cirrhosis, with the most marked circulatory disturbances, are unknown. To test the hypothesis that there is an altered vascular response to ET-1, which may contribute to vasodilatation in advanced cirrhosis, we measured the in vivo responses to an intra-arterial infusion of ET- 1 in the forearm vascular bed of patients with advanced cirrhosis before and after liver transplantation, and in healthy control subjects. To explore the mechanisms responsible for these responses we determined the contribution of the $\mathrm{ET}_{\mathrm{A}}$ receptor to maintenance of vascular tone in patients awaiting

\footnotetext{
Abbreviations: $A U C$, area under the curve; $E T-1$, endothelin-1; $\mathrm{ET}_{\mathrm{A}_{1}}$ endothelin $A$ receptor; $E_{B}$, endothelin $B$ receptor; $E D R F$, endothelium derived relaxing factors; NO, nitric oxide; $\mathrm{CO}$, cardiac output; $\mathrm{CVP}$, central venous pressure; RAP, right atrial pressure; $\mathrm{Cl}$, cardiac index; SVRI, systemic vascular resistance index; MAP, mean arterial pressure; $H R$, heart rate; eNOS, endothelial nitric oxide synthase
} 
liver transplantation by studying the effects of the selective $\mathrm{ET}_{\mathrm{A}}$ antagonist BQ123. ${ }^{13}$

\section{MATERIALS AND METHODS Subjects}

Twelve patients with advanced cirrhosis requiring liver transplantation and 12 age and sex matched healthy control subjects took part in the study. In the first part (protocol 1), peripheral vascular responses to intra-arterial ET-1 were examined in six of the cirrhosis patients (cirrhosis group 1) and in six control subjects (control group 1). Five of the six cirrhosis patients (cirrhosis group 1) were subsequently restudied following successful liver transplantation. The sixth patient declined the invitation to be restudied following his transplant. The timing of the repeat study varied from 47 to 329 days post transplant (mean 186 (47) days). In a separate series of experiments (protocol 2), the contribution of the $\mathrm{ET}_{\mathrm{A}}$ receptor to maintenance of forearm vascular tone was determined in the remaining six cirrhotic patients (cirrhosis group 2). This was achieved by measuring forearm blood flow responses to an intra-arterial infusion of the selective $\mathrm{ET}_{\mathrm{A}}$ receptor antagonist $\mathrm{BQ} 123$. Comparisons were made with a second control group of six age and sex matched individuals (control group 2).

In all cirrhosis patients, the diagnosis was established on the basis of liver histology or the presence of consistent clinical and radiological findings. At the time of writing, all of the patients have undergone successful liver transplantation with the exception of one patient who remains on the transplant waiting list. All cirrhosis and control subjects were current non-smokers and patients had not consumed alcohol for a minimum of six months prior to the study as this has known depressive effects on vascular reactivity. ${ }^{14}$ In the control subjects, liver disease was excluded on the basis of clinical history and examination.

All subjects were instructed to fast overnight and to abstain from caffeine containing beverages for at least 12 hours prior to the study. None of the control participants took regular medication. To avoid unacceptable clinical deterioration, no changes were made to the current drug therapy of any of the cirrhotic patients, but to avoid acute dosing effects, all medications were withheld on the morning of the study. All the cirrhosis patients had a history of ascites and, with the exception of one patient (in cirrhosis group 2), were on diuretic therapy (spironolactone 50-300 mg/day; frusemide 20-120 mg/day; amiloride $20 \mathrm{mg} /$ day). Four patients were taking non-selective beta blockers (two in each of the cirrhosis groups) although the dosage was relatively low in three patients ( $40 \mathrm{mg} /$ day or less). One patient was on isosorbide mononitrate (cirrhosis group 1). The remaining medications (and number of patients in parentheses) were as follows: lactulose (7), proton pump inhibitors (7), vitamin K (4), norfloxacin (2), neomycin (1), ursodeoxycholic acid (1), and lamivudine (1). When re-examined post transplant, all patients were receiving triple immunosuppressive therapy with prednisolone, azathioprine, and either cyclosporin or tacrolimus, but these were all withheld on the day of testing until completion of the study. Written informed consent was obtained in all instances. The study had the approval of the institutional ethics committee (Alfred Hospital, and Austin and Repatriation Medical Centre) and adhered to the principles of the Declaration of Helsinki.

\section{Measurement of forearm blood flow}

All studies were performed in the morning and took place in a quiet room maintained at a temperature of $21-24^{\circ} \mathrm{C}$. Subjects were rested supine throughout the entire study. The brachial artery of the non-dominant arm was cannulated using a full aseptic technique using a 3 French needle (Cook
Radial Catheterisation Set; Cook, QLD, Australia) under local anaesthetic (1\% lignocaine; AstraZeneca, Sydney, Australia). The arterial cannula was attached to a pressure transducer (Biosensors International Pty Ltd, Singapore) and patency maintained with heparinised saline (Baxter, Toongambie, Australia). As neither ET-1 nor BQ123 had been infused previously in patients with advanced cirrhosis, blood pressure and heart rate were monitored closely throughout the study in the non-cannulated arm using a Dinamap automatic blood pressure recorder (Critikon Inc.; Tamp, Florida, USA). Forearm blood flow was monitored for at least 30 minutes after brachial artery catheterisation and a stable baseline obtained prior to drug infusion.

Forearm blood flow was measured using the technique of forearm plethysmography, as described previously. ${ }^{15}$ A sealed, alloy filled, double stranded strain gauge was applied to the widest aspect of the forearm and attached to a plethysmograph (Medasonic; Mountain View, California, USA). Recordings were made for 10 seconds out of every 20 seconds. Venous outflow was occluded at the upper arm with a rapid cuff inflator (E20, Hokanson Inc; Bella, Western Australia) at a pressure of 40-50 mm Hg. Hand circulation was excluded prior to recordings by another cuff manually inflated to $200 \mathrm{~mm} \mathrm{Hg}$. At each time point, an average of at least three forearm blood flow readings were taken approximately one minute after wrist cuff inflation.

\section{Study design}

As outlined above, the two protocols were applied as separate stand alone studies to two distinct groups of cirrhotics and controls (protocols 1 and 2). In the first protocol (protocol 1), changes in forearm blood flow were measured in response to intra-arterial infusion of ET-1 (Clinalfa, AG, Läufelfingen, Switzerland) ( $5 \mathrm{pmol} / \mathrm{min}$ given at $1 \mathrm{ml} / \mathrm{min}$ for 60 minutes). The dose of ET-1 was based on previously published work demonstrating approximately $50 \%$ reduction in forearm blood flow after 60 minutes of ET-1 infusion in normal healthy volunteers. ${ }^{16}$ Subjects studied under protocol 2 (control and cirrhosis group 2) were infused via the brachial artery with the selective $\mathrm{ET}_{\mathrm{A}}$ receptor antagonist BQ123 ( $10 \mathrm{nmol} / \mathrm{min} ; 2 \mathrm{ml} / \mathrm{min}$, coinfused with saline at $4 \mathrm{ml} / \mathrm{min}$ for 60 minutes). In both protocols, measurements of forearm blood flow were taken at baseline and at five minute intervals during drug infusion. Forearm blood flow was expressed as percentage change in flow from baseline $(\% \Delta \mathrm{FBF})$.

\section{Invasive haemodynamics}

In all but one of the patients with cirrhosis, invasive measurements of cardiac output (CO), central venous pressure (CVP), and right atrial pressure (RAP) were undertaken immediately prior to transplantation using a pulmonary artery catheter. Cardiac index (CI) was calculated as the quotient of CO $(\mathrm{l} / \mathrm{min})$ over body surface area $\left(\mathrm{m}^{2}\right)$. Systemic vascular resistance (SVRI) was derived according to the formula: $\quad$ SVRI $=(79.9 \times(\mathrm{MAP}-\mathrm{CVP}) / \mathrm{CI}) \quad($ normal value $1760-2600$ dyn $\left.\times \mathrm{s} / \mathrm{cm}^{5} / \mathrm{m}^{2}\right)$.

\section{Plasma assays of ET- 1}

An arterial sample was taken from the brachial artery of patients with cirrhosis and from healthy control subjects undergoing the forearm studies. Blood was collected into tubes containing EDTA and immediately centrifuged at $2000 \mathrm{~g}$ for 10 minutes. Plasma was removed and stored at $-80^{\circ} \mathrm{C}$ for subsequent analysis. Endothelin was extracted by passage of each sample through a C2 minicolumn (RPN1903; Amersham Pharmacia Biotech, UK); free endothelin was then quantified by radioimmunoassay. This was achieved using commercially available antibodies and $\left[{ }^{125} \mathrm{I}\right] \mathrm{ET}-\mathrm{I}$ in a competitive double antibody assay (RPA545; Amersham 
Pharmacia Biotech). Sample counting and standard curve interpolation were performed on a RIAStar gamma counter (model A545; Packard Instrument Co, Illinois, USA). Cross reactivities of the endothelin assay were endothelin-1 $(100 \%)$, endothelin-3 (0\%), and big endothelin-1 (189\%).

\section{Statistical analysis}

Mean forearm blood flow for each recording period during drug infusion was calculated and expressed as a percentage of blood flow at baseline. The collection of points obtained was compared using two way ANOVA with and without repeated measures, as appropriate. The area under each individual blood flow versus time curve was also calculated, and the mean value of the area under the curve (AUC) for each group was compared using paired and unpaired Student's $t$ tests, as appropriate. Data were expressed as mean (SEM) values, and comparisons made using paired and unpaired Student's $t$ tests and ANOVA, as appropriate. A p value of $<0.05$ was considered statistically significant.

\section{RESULTS}

\section{Subjects}

The characteristics of each study group, including the causes of liver disease, are detailed in table 1. Each group of patients with cirrhosis was well matched for age and sex with their corresponding control groups, with no overall difference in mean age between each group $(\mathrm{p}=0.66$, ANOVA) (table 1$)$. Cirrhosis patients had evidence of advanced disease (ChildPugh grade C), with both groups showing similar disease severity, as measured by the Child-Pugh score, serum albumin, bilirubin, and prothrombin time.

\section{Haemodynamic parameters and baseline forearm blood flow}

Baseline forearm blood flow was comparable between all subjects, with no significant differences between the control and cirrhosis groups (table 2). Baseline heart rate (HR) in the cirrhosis groups was not significantly different from controls, and although there was a trend to a reduced MAP by cuff measurement in the cirrhotic groups, this did not achieve statistical significance ( $p=0.16$, ANOVA).

A hyperdynamic circulation was confirmed via a pulmonary artery catheter in cirrhosis patients, with a high resting mean CO (cirrhosis group l: 8.60 (0.54) l/min; cirrhosis group 2: 7.76 (0.75) l/min (normal range 3.5-5.5 l/min)) and a low mean SVRI (cirrhosis group 1: 1119 (89.9); cirrhosis group 2: 1481 (207) (normal range 1760-2600 dyn $\left.\times \mathrm{s} / \mathrm{cm}^{5} / \mathrm{m}^{2}\right)$ ).

\section{Responses to ET-1 infusion: protocol 1}

The response to infused ET-1 was significantly different in patients with cirrhosis compared with controls (fig 1A), with an increase in forearm flow in the cirrhosis group observed over 60 minutes compared with a reduction in flow in the control group $(\mathrm{p}<0.0001$, cirrhosis $v$ control responses, two way ANOVA). Measurement of mean AUC under each response curve for the cirrhosis group showed an overall vasodilatation response compared with a vasoconstriction response in the control group $(\mathrm{p}<0.0001$, AUCs of cirrhosis $v$ control responses; fig 1B). In keeping with the subsystemic

\begin{tabular}{|c|c|c|c|c|}
\hline Subject characteristic & $\begin{array}{l}\text { Cirrhosis group } 1 \\
\text { (ETI) }\end{array}$ & $\begin{array}{l}\text { Control group } 1 \\
\text { (ETI) }\end{array}$ & $\begin{array}{l}\text { Cirrhosis group } 2 \\
\text { (BQ123) }\end{array}$ & $\begin{array}{l}\text { Control group } 2 \\
\text { (BQ123) }\end{array}$ \\
\hline No of subjects & 6 & 6 & 6 & 6 \\
\hline Age $(y)$ & $51.3(2.4)$ & $49(4)$ & $46.3(1.6)$ & $47.8(2.9)$ \\
\hline $\operatorname{Sex}(M / F)$ & $6 / 0$ & $6 / 0$ & $5 / 1$ & $5 / 1$ \\
\hline Albumin $(g / d l)$ & $26.7(2.4)$ & - & $27.0(1.6)$ & - \\
\hline Bilirubin ( $\mu \mathrm{mol} / \mathrm{l})$ & $48.0(15.3)$ & - & $114.7(68.7)$ & - \\
\hline Prothrombin time (s) & $19.7(1.6)$ & - & $16.2(1.6)$ & - \\
\hline \multicolumn{5}{|l|}{ Aetiology } \\
\hline Hepatitis B virus & 1 & - & - & - \\
\hline Hepatitis C virus & - & - & 5 & - \\
\hline Non-alcoholic steatohepatitis & 1 & - & - & - \\
\hline Alcoholic liver disease & 3 & - & - & - \\
\hline Cryptogenic & 1 & - & - & - \\
\hline Primary biliary cirrhosis & - & - & 1 & - \\
\hline Child-Pugh score & $11.7(0.76)$ & - & $10.5(0.32)$ & - \\
\hline Child-Pugh class & $C(n=6)$ & - & $C(n=6)$ & - \\
\hline
\end{tabular}

Table 2 Haemodynamic parameters for the study subjects

\begin{tabular}{|c|c|c|c|c|}
\hline & $\begin{array}{l}\text { Cirrhosis group } 1 \\
\text { (ETI) }\end{array}$ & $\begin{array}{l}\text { Control group } 1 \\
\text { (ET1) }\end{array}$ & $\begin{array}{l}\text { Cirrhosis group } 2 \\
\text { (BQ123) }\end{array}$ & $\begin{array}{l}\text { Control group } \\
2 \text { (BQ123) }\end{array}$ \\
\hline MAP $(\mathrm{mm} \mathrm{Hg})$ & $78(5.1)$ & $87(3.7)$ & $80.3(5.0)$ & $90.8(2.8)$ \\
\hline $\mathrm{HR}$ (bpm) & $73(6.0)$ & $70(6.1)$ & $66.5(2.4)$ & $57.7(2.8)$ \\
\hline $\begin{array}{l}\text { Baseline } \mathrm{FBF}(\mathrm{ml} / 100 \mathrm{ml} \\
\text { forearm volume } / \mathrm{min})\end{array}$ & $2.87(0.59)$ & $2.10(0.58)$ & $2.35(0.22)$ & $2.77(0.39)$ \\
\hline \multicolumn{5}{|c|}{ Invasive haemodynamic measurements } \\
\hline MAP (arterial line) & $68.8(3.89)(n=6)$ & - & $71.6(7.53)(n=5)$ & - \\
\hline Cardiac output (I/min) & $8.60(0.54)(n=6)$ & - & $7.76(0.75)(n=5)$ & - \\
\hline SVRI $\left(\right.$ dyn $\left.\times s / \mathrm{cm}^{5} / \mathrm{m}^{2}\right)$ & $1119(89.89)(n=6)$ & - & $1481(207)(n=5)$ & - \\
\hline
\end{tabular}

Invasive measurements of mean arterial pressure (MAP), cardiac output (CO), and systemic vascular resistance index (SVRI) were taken immediately pretransplant via a pulmonary artery catheter.

$H R$, heart rate; FBF, forearm blood flow. 

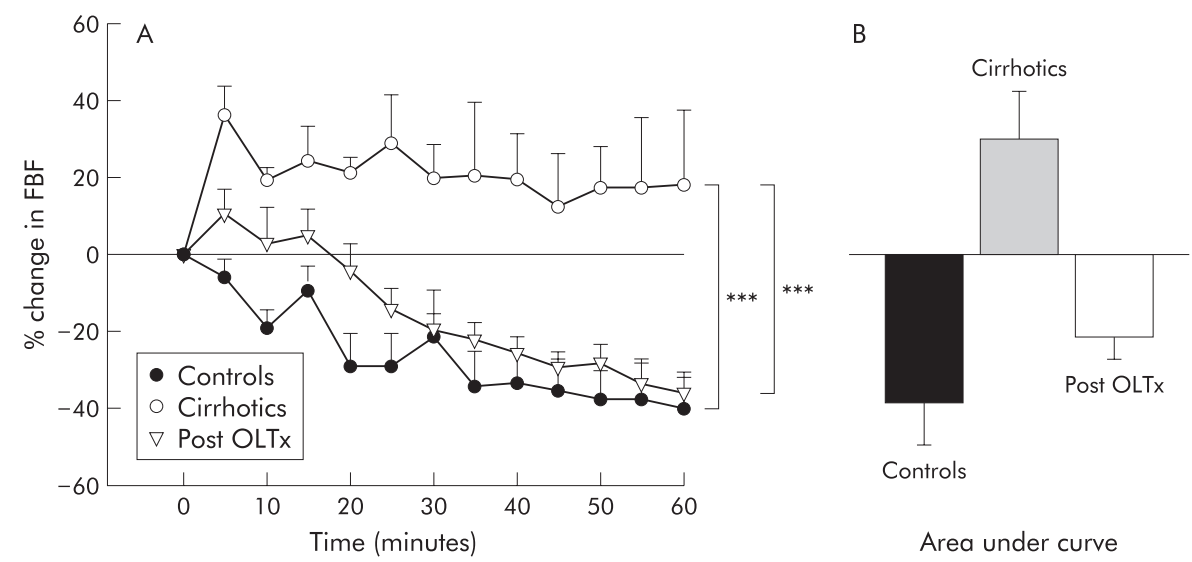

Figure 1 (A) Forearm blood flow (FBF) response to an intra-arterial infusion of endothelin-1 (ET-1) over 60 minutes in patients with advanced cirrhosis, before and after liver transplantation, and in healthy control subjects. Flow is expressed as percentage change from baseline flow. The blood flow response in patients with cirrhosis was significantly different from that of controls (*** $p<0.0001$, two way ANOVA) and the response post transplant ( ${ }^{* * *} p<0.0001$, two way repeated measures ANOVA). (B) Mean area under the curve for each group is shown. The cirrhosis group demonstrated an overall vasodilatation response compared with that of control subjects $(p<0.001)$ and was significantly different from the post transplant value $(p<0.05)$. There was no significant difference between the post transplant value and that of the control group ( $p>0.05)$. Post OLTx, post transplant.

dose of ET-1 used, HR and blood pressure did not alter significantly in either group during infusion (data not shown).

Following liver transplantation, baseline blood pressure and HR were not significantly different in patients compared with controls but blood pressure was higher than pretransplant levels $(p<0.05)$. Baseline forearm blood flow was not different from pretransplant and control levels $(p=0.61)$. The blood flow response to infused ET-1 post transplant reverted to one of vasoconstriction, resembling that of control subjects (post transplant $v$ control; $\mathrm{p}=0.87$, two way ANOVA). When the AUCs for each response curve were compared (fig 1B), there was no difference between the post transplant response and healthy controls but there was a significant difference from the pretransplant vasodilatation response $(\mathrm{p}<0.05)$.

\section{Responses to $B Q 123$ infusion: protocol 2}

Infusion of BQ123 increased forearm blood flows in both cirrhosis and control subjects (fig 2A). There was no difference in the degree of vasodilatation observed (cirrhosis $v$ control; $\mathrm{p}=0.89$, two way ANOVA) and no overall difference in the AUC (fig 2B) between groups $(p=0.94)$.

\section{Blood assays}

There was no significant difference in arterial plasma endothelin levels between patients with cirrhosis and control subjects (cirrhosis: 7.81 (1.24) fmol $/ \mathrm{ml}, \mathrm{n}=10$; controls: 7.34 (1.47) $\mathrm{fmol} / \mathrm{ml}, \mathrm{n}=7 ; \mathrm{p}=0.81$ ).

\section{DISCUSSION}

Endothelin-1 is a potent vasoactive peptide produced by the vascular endothelium. It acts predominantly as a paracrine vasoconstrictor, regulating vascular tone through its action on $\mathrm{ET}_{\mathrm{A}}$ and $\mathrm{ET}_{\mathrm{B}}$ receptors ${ }^{11}$ on adjacent vascular smooth muscle. However, ET-l has also been reported to exert a vasodilatory influence via $\mathrm{ET}_{\mathrm{B}}$ receptors on the endothelium, by triggering release of EDRFs such as $\mathrm{NO} \cdot{ }^{17}$ In health, the constrictor effect of ET-l on vascular smooth muscle predominates over endothelium dependent vasodilatation, and administration of ET-1 to normal subjects produces significant vasoconstriction, ${ }^{16}$ similar in degree to that

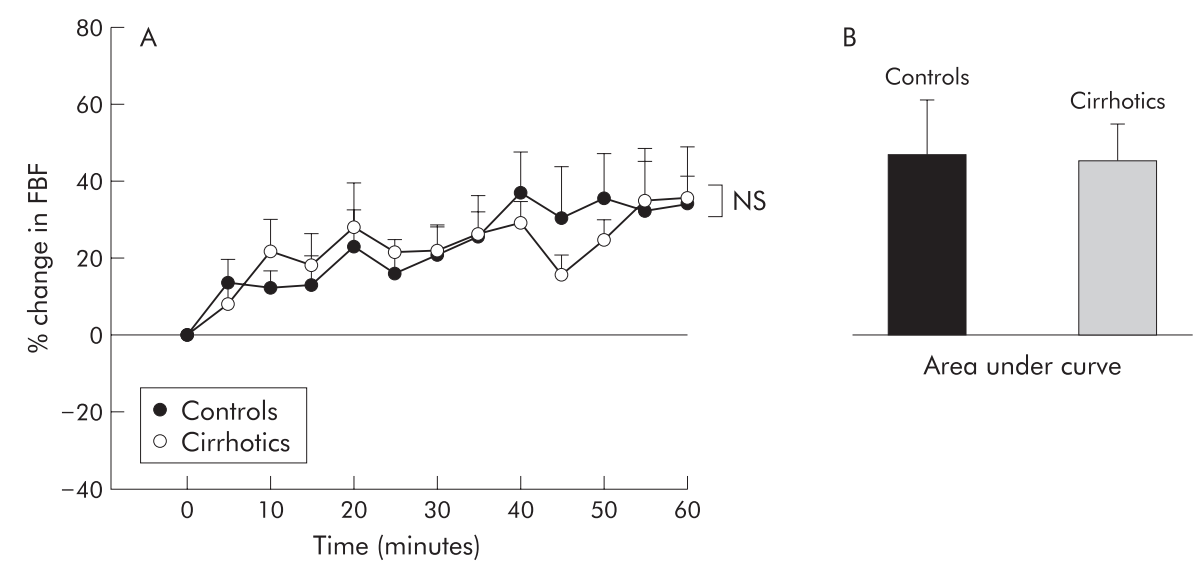

Figure 2 (A) Forearm blood flow (FBF) response to an intra-arterial infusion of the ETA receptor antagonist, BQ123, over 60 minutes in patients with advanced cirrhosis (before transplantation) and in healthy control subjects. Flow is expressed as percentage change from baseline flow. The blood flow response in patients with cirrhosis was the same as that in controls ( $p=0.99$, two way ANOVA). (B) Mean area under the curve for each group is shown. There was no significant difference in the degree of overall vasodilatation observed between the cirrhosis and control groups. 
observed in the current study. In a recent study in compensated cirrhotics who were not vasodilated, the normal vasoconstriction response to ET-1 was found to be preserved, although blunted, compared with that of controls. ${ }^{12}$ In contrast, we found that in our patients with advanced cirrhosis and a hyperdynamic circulation, ET-l infusion caused significant peripheral vasodilatation. This indicates that in patients with advanced liver disease and more intense activation of vasoconstrictor systems, endothelin may lead to vasodilatation as a result of enhancement of $\mathrm{ET}_{\mathrm{B}}$ receptor mediated vasodilatation, an effect that appears to outweigh the $\mathrm{ET}_{\mathrm{A}}$ mediated vasoconstriction response.

This proposed mechanism is supported by demonstration of elevated NO levels ${ }^{18}$ and enhanced vasodilatation in response to a number of endothelium and NO dependent vasodilators in the forearm vasculature of patients with cirrhosis. ${ }^{15}{ }^{19-21}$ ET-1 induced vasodilatation has been recently demonstrated in the pulmonary circulation of experimental animals with portal hypertension. ${ }^{22}$ In this setting, vasodilatation was associated with increased levels of lung endothelial nitric oxide synthase (eNOS) and increased NO production. The role of the $\mathrm{ET}_{\mathrm{B}}$ receptor in mediating this increase in eNOS expression is suggested by the observation that, in cell culture, $\mathrm{ET}_{\mathrm{B}}$ receptor blockade prevents endothelin mediated increases in eNOS expression. ${ }^{22} 23$

Another possible mechanism is a dampening of $\mathrm{ET}_{\mathrm{A}}$ receptor mediated vasoconstriction responses so that $\mathrm{ET}_{\mathrm{B}}$ mediated vasodilatation becomes the predominant response to infused ET-1. If this were the case, vasodilatation following blockade of the $\mathrm{ET}_{\mathrm{A}}$ receptor would be expected to be reduced in cirrhosis. ${ }^{12}$ This response was not different in the two groups studied, suggesting that alterations in $\mathrm{ET}_{\mathrm{A}}$ receptor responses are not primarily responsible for the abnormal vasodilatory response observed to infused ET-1 in cirrhotic patients pretransplantation.

Forearm blood flow in our patients with advanced liver failure was found to be normal at baseline. However, at the time of liver transplantation, a markedly hyperdynamic and vasodilated circulation was confirmed in this patient group, indicating that other vascular beds remained dilated. Previous workers have also shown a normal forearm blood flow in this setting. ${ }^{24}$ In advanced cirrhosis, vasodilatation leads to compensatory activation of several vasoconstrictor systems and elevation of circulating levels of vasopressors such as angiotensin $\mathrm{II}^{25}$ noradrenaline, ${ }^{26}$ and arginine vasopressin. $^{27}$ Our findings suggest that this activation maintains normal flow in the forearm (rather than inducing vasoconstriction) but is insufficient to overcome vasodilatation in other vascular beds.

Elevated levels of ET-1 have been described in the systemic venous $^{28} 29$ and splanchnic venous circulations ${ }^{30}$ of patients with cirrhosis. Less is known about the levels of ET-1 in the forearm arterial circulation of these patients, although there is evidence of elevated levels in blood obtained from the femoral artery..$^{29}$ In the present study, we found no significant elevation in plasma ET-1 levels in forearm arterial blood from our patients with cirrhosis. The reason for such a discrepancy is unclear, although it may in part relate to the different vascular site from which blood was obtained as well as the choice and specificity of the immunoassay used in the present study. It may also indicate that there is enhanced pulmonary clearance of ET- 1 in advanced cirrhosis, possibly as a result of upregulation of the pulmonary $\mathrm{ET}_{\mathrm{B}}$ receptor. ${ }^{23}$ Importantly, basal flow and ET-1 concentrations in our patients were the same as in controls and therefore the amount of ET-1 (infused plus background) delivered to the forearm in the two groups was identical. Thus it is likely that the marked difference in blood flow response to ET-1 observed in our study reflects altered vascular activity, rather than differences in ET-1 delivery.

In conclusion, we have shown that infusion of endothelin1 (ET-1) induces vasodilatation in the forearm vasculature of patients with advanced cirrhosis at a dose that causes marked vasoconstriction in normal subjects. Furthermore, in keeping with resolution of the vasodilatation that has been described in a number of vascular beds post transplant, ${ }^{32}{ }^{33}$ we have demonstrated that the normal vasoconstrictor response to exogenous ET- 1 is restored following successful liver transplantation. These findings suggest a possible role for ET-1 in the pathophysiology of the systemic vasodilatation of cirrhosis.

\section{ACKNOWLEDGEMENTS}

The authors wish to thank Ms Jennifer Starr and Ms Ann-Maree Jefferis for their assistance with subject recruitment and the experimental protocol. Dr Vaughan is the recipient of an Austin Hospital Medical Research Foundation Scholarship. This work was supported by grants made available by the Alfred Hospital Research Trust, and the Austin Hospital Medical Research Foundation.

\section{Authors' affiliations}

R B Vaughan, P W Angus, Victorian Liver Transplant Unit, Austin and Repatriation Medical Centre, Studley Rd, Heidelberg, Melbourne, VIC 3084, Australia

J P F Chin-Dusting, Wynn Domain, Baker Heart Research Institute, Commercial Rd, Prahran, VIC 3181, Australia

\section{REFERENCES}

1 Murray JF, Dawson AM, Sherlock S. Circulatory changes in chronic liver disease. Am J Med 1958;24:358-67.

2 Kotelanski B, Groszmann RJ, Cohn JN. Circulation times in the splanchnic and hepatic beds in alcoholic liver disease. Gastroenterology 1972;63:102-1 1.

3 Groszmann RJ. Hyperdynamic state in chronic liver diseases. J Hepatol 1993; 17:S38-40.

4 Floras JS, Legault L, Morali GA, et al. Increased sympathetic outflow in cirrhosis and ascites: direct evidence from intraneural recordings. Ann Intern Med 1991;114:373-80.

5 Schrier RW, Arroyo V, Bernardi M, et al. Peripheral arterial vasodilation hypothesis: a proposal for the initiation of renal sodium and water retention in cirrhosis. Hepatology 1988;8:1151-7.

6 MacGilchrist AJ, Sumner D, Reid JL. Impaired pressor reactivity in cirrhosis: evidence for a peripheral vascular defect. Hepatology 1991;13:689-94.

7 Islam MZ, Williams BC, Madhavan KK, et al. Selective alteration of agonistmediated contraction in hepatic arteries isolated from patients with cirrhosis. Gastroenterology 2000;1 18:765-71.

8 Tage-Jensen U, Henriksen JH, Christensen E, et al. Plasma catecholamine level and portal venous pressure as guides to prognosis in patients with cirrhosis. $J$ Hepatol 1988;6:350-8.

9 Sumner MJ, Cannon TR, Mundin JW, et al. Endothelin ETA and ETB receptors mediate vascular smooth muscle contraction. Br J Pharmacol 1992; 107:858-60.

10 Strachan FE, Spratt JC, Wilkinson IB, et al. Systemic blockade of the endothelin-B receptor increases peripheral vascular resistance in healthy men. Hypertension 1999;33:581-5.

11 Verhaar MC, Strachan FE, Newby DE, et al. Endothelin-A receptor antagonist-mediated vasodilatation is attenuated by inhibition of nitric oxide synthesis and by endothelin-B receptor blockade. Circulation 1998:97:752-6.

12 Helmy A, Jalan R, Newby DE, et al. Altered peripheral vascular responses to exogenous and endogenous endothelin-1 in patients with well-compensated cirrhosis. Hepatology 2001;33:826-31.

13 Helmy A, Jalan R, Newby DE, et al. Altered peripheral vascular responses to exogenous and endogenous endothelin-1 in patients with well-compensated cirrhosis. Hepatology 2001;33:826-31.

14 Howes LG, Reid JL. Decreased vascular responsiveness to noradrenaline following regular ethanol consumption. $\mathrm{Br} J$ Clin Pharmacol 1985;20:669-74.

15 Chin-Dusting JP, Rasaratnam B, Jennings GL, et al. Effect of fluoroquinolone on the enhanced nitric oxide-induced peripheral vasodilation seen in cirrhosis. Ann Intern Med 1997; 127:985-8.

16 Haynes WG, Strachan FE, Gray GA, et al. Forearm vasoconstriction to endothelin-1 is mediated by ETA and ETB receptors in vivo in humans. $J$ Cardiovasc Pharmacol 1995;26(suppl 3):S40-3.

17 Hirata Y, Emori T, Eguchi S, et al. Endothelin receptor subtype B mediates synthesis of nitric oxide by cultured bovine endothelial cells. J Clin Invest 1993;91:1367-73.

18 Campillo B, Chabrier PE, Pelle G, et al. Inhibition of nitric oxide synthesis in the forearm arterial bed of patients with advanced cirrhosis. Hepatology 1995;22:1423-9. 
19 Albillos A, Rossi I, Cacho G, et al. Enhanced endothelium-dependent vasodilation in patients with cirrhosis. Am J Physiol 1995;268:G459-64.

20 Rongen GA, Smits P, Thien T. NG-monomethyl-L-ARG reduces the forearm vasodilator response to acetylcholine but not to methacholine in humans. J Cardiovasc Pharmacol 1993;22:884-8.

21 Chowienczyk PJ, Cockcroft JR, Ritter JM. Differential inhibition by NGmonomethyl-L-arginine of vasodilator effects of acetylcholine and methacholine in human forearm vasculature. Br J Pharmacol 1993:110:736-8

22 Zhang M, Luo B, Chen SJ, et al. Endothelin-1 stimulation of endothelial nitric oxide synthase in the pathogenesis of hepatopulmonary syndrome. Am J Physiol 1999;277:G944-52.

23 Fallon MB, Abrams GA. Pulmonary dysfunction in chronic liver disease. Hepatology 2000:32:859-65.

24 Newby DE, Jalan R, Masumori S, et al. Peripheral vascular tone in patients with cirrhosis: role of the renin-angiotensin and sympathetic nervous systems. Cardiovasc Res 1998;38:221-8.

25 Helmy A, Jalan R, Newby DE, et al. Role of angiotensin II in regulation of basal and sympathetically stimulated vascular tone in early and advanced cirrhosis. Gastroenterology 2000;1 18:565-72.

26 Nicholls KM, Shapiro MD, Van Putten VJ, et al. Elevated plasma norepinephrine concentrations in decompensated cirrhosis. Association with increased secretion rates, normal clearance rates, and suppressibility by central blood volume expansion. Circ Res 1985;56:457-61.

27 Bichet D, Szatalowicz V, Chaimovitz C, et al. Role of vasopressin in abnormal water excretion in cirrhotic patients. Ann Intern Med 1982;96:413-17.

28 Asbert M, Gines A, Gines P, et al. Circulating levels of endothelin in cirrhosis. Gastroenterology 1993; 104:1485-91.

29 Moller S, Gulberg V, Henriksen JH, et al. Endothelin-1 and endothelin-3 in cirrhosis: relations to systemic and splanchnic haemodynamics. J Hepatol 1995;23: 135-44.

30 Nolte W, Ehrenreich H, Wiltfang J, et al. Systemic and splanchnic endothelin1 plasma levels in liver cirrhosis before and after transjugular intrahepatic portosystemic shunt (TIPS). Liver 2000;20:60-5.

31 Gerbes AL, Moller S, Gulberg V, et al. Endothelin-1 and -3 plasma concentrations in patients with cirrhosis: role of splanchnic and renal passage and liver function. Hepatology 1995;21:735-9.

32 Battaglia SE, Pretto JJ, Irving LB, et al. Resolution of gas exchange abnormalities and intrapulmonary shunting following liver transplantation. Hepatology 1997:25:1228-32.

33 Navasa M, Feu F, Garcia-Pagan JC, et al. Hemodynamic and humoral changes after liver transplantation in patients with cirrhosis. Hepatology 1993;17:355-60.

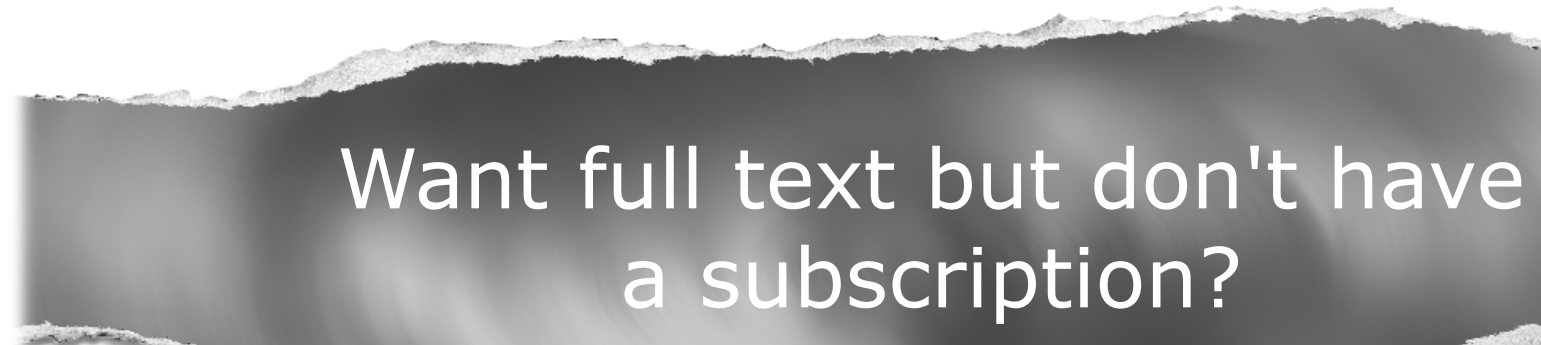

\section{Pay per view}

For just $\$ 8$ you can purchase the full text of individual articles using our secure online ordering service. You will have access to the full text of the relevant article for 48 hours during which time you may download and print the pdf file for personal use.

www.gutjinl.com 